\title{
Carnets
}

Revue électronique d'études françaises de l'APEF

Première Série - 4 Numéro Spécial | 2012

Invasions \& Évasions

\section{Literatura ou a arte de contar a História: bibliografia alusiva às Campanhas Peninsulares}

\section{Margarida Reffóios}

\section{CpenEdition}

1 Journals

\section{Edição electrónica}

URL: http://journals.openedition.org/carnets/7347

DOI: 10.4000/carnets.7347

ISSN: 1646-7698

\section{Editora}

APEF

Edição impressa

Data de publição: 1 Junho 2012

Paginação: 63-70

\section{Refêrencia eletrónica}

Margarida Reffóios, «Literatura ou a arte de contar a História: bibliografia alusiva às Campanhas Peninsulares », Carnets [Online], Première Série - 4 Numéro Spécial | 2012, posto online no dia 23 junho 2018, consultado o 02 maio 2019. URL : http://journals.openedition.org/carnets/7347 ; DOI : 10.4000/ carnets.7347

\section{(c) (i) \&}

Carnets est mis à disposition selon les termes de la licence Creative Commons - Atribution - Pas d'utilisation commerciale 4.0 International. 


\title{
LITERATURA OU A ARTE DE CONTAR A HISTÓRIA Bibliografia alusiva às Campanhas Peninsulares
}

\author{
MARGARIDA REFFÓIOS \\ Universidade de Évora /CEL \\ mgsr@uevora.pt
}

\begin{abstract}
Resumo
Nesta comunicação, pretendemos dar conta, em primeiro lugar, de alguns dos textos escritos por autores / intervenientes franceses durante as Invasões Francesas, como Laure Permont (Duquesa de Abrantes) ou Jacome Ratton. Em segundo lugar, procuraremos referir alguns dos muitos escritos portugueses relativos a essa mesma época. Referindo idiologias opostas, podemos afirmar que a bibliografia alusiva às Campanhas Peninsulares é densa e conduz-nos a dois planos de observação muito férteis: a literatura dita científica e o romance histórico. Em último lugar, tentaremos analisar a nova bibliografia que "renasceu" com as comemorações $\left(2^{\circ}\right.$ centenário) da presença dos franceses em Portugal, citando autores como Graça Moura ou Luz Soriano.
\end{abstract}

\begin{abstract}
With this paper, we firstly aim to present an account of some texts written by French authors /protagonists during the French Invasions, such as Laure Permont (Duchess of Abrantes) or Jacome Ratton. Secondly we will endeavour to mention some of the many Portuguese writings which date back to that period. By referring to opposed ideologies, we can affirm that the bibliography which concerns the Peninsular Campaigns is dense and leads us to two dimensions of fertile observation: the so-called scientific literature and the historical novel. Finally we will attempt at analysing the new bibliography which was 'reborn' with the commemoration (second centenary) of the French presence in Portugal, quoting authors such as Graça Moura or Luz Soriano.
\end{abstract}

Palavras Chave: Literatura Cientifica, Romance Histórico, Invasões Francesas.

Keywords: Scientific Literature, Historical Novel, French Invasions. 


\begin{abstract}
- E é francês ou espanhol?
- Fala francês como nós. Mas diz que é português, que é de Lisboa e que não anda na guerra. Também diz que conhece muito o nosso general Junot, que deixou o salvo-conduto numa casa logo acima de Portalegre e que veio tratar de um caso de vida ou de morte. (Graça Moura, 2008: 131)
\end{abstract}

\title{
Introdução
}

De acordo com os estudos literários mais recentes, a escrita da História durante o século XIX é, acima de tudo, uma escrita literária. Trata-se de uma actividade de homens de letras que escrevem para um público nutrido de humanidade, de retórica e estilo. O leitor da História é um leitor de histórias. Assim, constatamos que a História escreve-se na Literatura, não se confinando apenas ao espaço do romance histórico. Contar, analisar, julgar o passado - recente ou não - é uma tarefa comprometedora e apaixonante: "En tout premier lieu, l'écriture de l'histoire au XIXe siècle est, précisément, littéraire. C'est une activité d'hommes de lettres, qui écrivent pour un public nourri d'humanité, et plus encore, de rhétorique et de beau style" (Berthier ; Jarrety, 2006 :336).

Por outro lado, constatamos que também a escrita durante o século XIX assume um novo caminho que aponta para uma literatura científica, esta passando a ser uma realidade. Nessa época, os documentos são numerosos e cada vez mais importantes e, como passam a ser publicados, verifica-se um maior respeito pela verdade histórica.

Assim, o homem de letras que estuda a História passa a valorizar os talentos literários dos historiadores, procurando dar a conhecer ao leitor atento da época os feitos heroicos de determinadas figuras marcantes. Ou seja, a escrita literária assume uma função de relevo na medida em que perpétua dados históricos que, na ausência desses testemunhos literários, de algum modo se teriam perdido no tempo.

Devemos, ainda, ter em linha de conta que este período histórico é, por si só, único: acontecimentos políticos aliados a correntes de ideias e movimentos literários de grande relevo levam a Europa a olhar para a França como o modelo a seguir. Apesar dos seus 7 regimes políticos ("Consulat", Império, Restauração, Monarquia de Julho, Segunda República e Terceira República), a França do século XIX é o país da liberdade e também o da ciência (Pasteur, Comte e outros).

De acordo com estas premissas, parece-me importante afirmar que a bibliografia alusiva às Campanhas Peninsulares é densa e conduz-nos a dois planos de observação muito férteis: a literatura dita científica (do domínio da História) e o romance histórico (do domínio do literário). 


\title{
I. A memória dos Franceses ou a Literatura Científica
}

É impossível falar da literatura relativa às Invasões Francesas sem referir o extenso trabalho que tem sido feito pelo Professor António Ventura. De forma muito clara, este autor tem recolhido e analisado dados de enorme importância fornecendo uma lista de toda a literatura autobiográfica sobre a Guerra Peninsular. Diz o autor que:

\begin{abstract}
Este período da História da Europa que se iniciou com a Revolução Francesa e que se prolongou até ao Congresso de Viena é um dos mais estudados. Dentro deste período, tem sido dada uma particular atenção às Guerras Napoleónicas e, de uma forma mais específica, à Guerra Peninsular - ou Guerra da Independência, como é conhecida em Espanha - sobre a qual abundam quer os estudos quer os depoimentos pessoais produzidos por muitos intervenientes directos ou indirectos (Ventura, 2008: 57).
\end{abstract}

Neste sentido, podemos avaliar dois tipos de literatura referente à matéria em causa: por um lado, existem referências nas bibliografias gerais sobre a época revolucionária, do directório, do consulado e do Império, como André Monglon na sua vasta obra La France Révolutionnaire et Impériale. Annales de bibliographie méthodique et description des livres illustrés. Ou ainda o levantamento específico elaborado por Jean Tullard, Nouvelle Bibliographie Critique des Mémoires sur l'Époque Napoléonienne écrits ou traduits en français, onde são referenciadas cerca de 1527 obras.

Através deste inventário conseguimos chegar a um outro género literário - as memórias - crucial na recuperação de pormenores relativos a um determinado período histórico e por vezes desvalorizados. De entre os militares franceses que integraram a Primeira Invasão, destacam-se algumas memórias das principais figuras de relevo.

Andoche Junot, comandante do Exército Francês, invadiu Portugal em Novembro de 1807 e foi nomeado Governador de Portugal, em nome de Napoleão. Elevado a "Duque de Abrantes", a sua ambição era grande, sendo chamado pelo povo de "El rei Junot". Não escreveu memórias - ao contrário de sua mulher - mas deixou um diário que reproduz toda a correspondência mantida com Napoleão Bonaparte. Trata-se de um documento precioso que acompanha o período de instalação dos franceses em Portugal.

André Masséna, Duque de Rivoli, Principe de Essling, viu as suas memórias escritas, na realidade, por um amigo e companheiro, o General Koch (1782-1861), homem dos sete ofícios (publicista, historiador, professor de direito, redactor, tradutor, etc...). Por ser um grande admirador de Masséna, Koch dedicou-se à pesquisa e recolha de materiais 
dispersos que dariam origem à obra Mémoires de Masséna, rédigés d'après les documents qu'il a laissés, et sur ceux du Dépôt de la Guerre et du Dépôt des Fortifications, par le général Koch. Tratando-se de um valioso contributo para a biografia de Masséna, é essencial para o entendimento da 3aㅡ Invasão Francesa a Portugal.

Jean-Baptiste Antoine Marcelin, Barão de Barbot, escreveu as suas memórias Mémoires du général baron de Marbot que acabariam por ser umas das mais conhecidas e populares sobre a época napoleónica. Ajudante-de-campo de Lannes e de Massena, também contribuiu em muito para a análise histórico-social da $3^{\underline{a}}$ invasão.

Poderia, ainda, relembrar autores como François Dainville, o Coronel André Delarave (que dá pormenores interessantes sobre as operações francesas nas Linhas de Torres) e muitos outros que redigiram documentos preciosos como o General Barão de Thiébault, que passo a citar:

Sur les bords même de ce torrent, M.Barreto, arrivant de Lisbonne, eut une conférence avec le général en chef. Les nouvelles qu'il apporta furent, qu'à la vérité, le Prince, informé que nous nous dispositions à entrer en Portugal, avoit ordonné que les habitants de la Beira-Alta nous en défendissent le passage, mais que dans l'étonnement de notre si rapide arrivée à Abrantès, il venoit de révoquer tous les ordres de cette nature: que dans cette situation tout se préparoit pour le départ du Prince, sans que cependant ce départ fût arrêté ; que le peuple étoit inquiet, le Gouvernement irrésolu (Apud Assis, 2008: 86).

Remetendo os interessados para os trabalhos de Ventura, prefiro escrever umas linhas sobre uma autora que me tem interessado e sobre a qual pretendo desenvolver alguma investigação mais rigorosa num futuro próximo: Laure St. Martin Permont Junot. Duquesa de Abrantes (1784-1838) deixou umas memórias que foram publicadas entre 1831-1834. Constituídas por 16 volumes de cerca de 350 páginas cada, apresentam, em geral, um bom estado de conservação. Escritas por uma das mulheres mais brilhantes da corte napoleónica e mulher de um dos melhores amigos de Napoleão - o Ajudante-deCampo Junot - este acervo constitui uma documentação preciosa sobre a vida do Imperador, relatando muitos episódios da sua vida íntima. Laure Permont usou o título como pseudónimo das suas memórias onde narrou, com grande pormenor, a sua passagem por Portugal, nomeadamente em 1805, quando o seu marido foi nomeado embaixador junto da Corte do Príncipe D. João. O que Madame Junot viu e fez em Lisboa consta destas memórias, cujo título Souvenirs d'une Ambassade et d'un Séjour en Espagne et en Portugal de 1808 à 1811 tem grande impropriedade de datas na parte que diz respeito a Portugal, onde o casal Junot viveu de finais de 1805 a Setembro de 1806. Entre digressões de acaso, a autora relata histórias de assassínios comandados ou petites histoires, e vai traçando 
perfis simpáticos de gente de corte que elogia. Os Souvenirs da Duquesa acabam, porém, com uma misteriosa história nocturna, nas cercanias da Penha Longa de Sintra, de pura tradição gótica. Muito do que é narrado deve, sem dúvida, ser filtrado e avaliado. Mas, tratase, sem dúvida, de um texto a explorar.

\section{A memória dos portugueses ou a Literatura Científica}

No que diz respeito às memórias portuguesas, a grande obra de referência é o Dicionário Bibliográfico da Guerra Peninsular de Cristovão Aires, que contem notas variadas.

De entre muitos dos catálogos que surgiram no $1^{\circ}$ Centenário da Guerra Peninsular, referimos aqui a título indicativo Nota acerca das Invasões Francesas em Portugal, principalmente respeitante à primeira invasão do comando de Junot de Brito de Aranha ou o Catálogo das Obras referentes à Guerra da Península de Cardoso de Bethencourt. Estes catálogos são organizados por temas, muitas vezes de forma confusa mas revelam a existência de vários livros de memórias sobre as campanhas de Portugal.

Devemos ainda acrescentar que, se por um lado, as memórias do Conde do Lavradio e do Marquês de Fronteira descrevem alguns dos episódios da Guerra Peninsular, por outro lado, não devemos deixar de aludir outros testemunhos não menos importantes e interessantes. Nomes como o de Jacome Raton que viveu em Portugal, acabando por se naturalizar português, representam registos fundamentais para entender o período das Invasões. Nas suas memórias existem pormenores que, em muito, contribuem para o entendimento dos factos históricos: Recordacoens de Jacome Ratton, fidalgo cavalleiro da Caza Real, cavalleiro da ordem de Christo, ex-negociante da praça de Lisboa, e deputado do tribunal supremo da Real Junta do Commercio, Agricultura, Fabricas e Navegação. Sobre occurrencias do seu tempo, em Portugal, durante o lapso de sessenta e tres annos e meio, aliás de maio de 1747 a setembro de 1810, que rezidio em Lisboa: acompanhadas de algumas subsequentes reflexoens suas, para informaçoens de seus proprios filhos. Com documentos no fim.

Também Simão José da Luz Soriano, na sua História da Guerra Civil e do estabelecimento do Governo Parlamentar compreendendo a história diplomática, militar e política, deste reino desde 1777 até 1834, descreve, em 16 volumes as relações do país ${ }^{1}$.

Outras referências interessantes surgem, por exemplo, com Camillo Luigi de Rossi (Núncio Apostólico em Lisboa) que, no seu Diário dos Acontecimentos de Lisboa por ocasião da entrada das Tropas de Junot, escrito por uma testemunha presencial, Camillo

\footnotetext{
${ }^{1}$ Lisboa, Imprensa Nacional, 1870.
} 
Luiz de Rossi, fornece pistas sobre a presença dos franceses em Lisboa ou José Teixeira de Mesquita, Barão das Lages, condecorado com a Cruz de Guerra das três Campanhas da Guerra Peninsular, que reflecte igualmente preocupações em Trinta e cinco anos de vida militar 1808-1834.

III. A Literatura das Invasões: um compromisso contemporâneo (Romance Histórico)

Com as comemorações do $2^{0}$ centenário das Invasões Francesas, uma nova bibliografia alusiva a esta temática tem surgido. Aqui vamos apenas referir dois autores: Pulido Valente e Graça Moura.

Pulido Valente em Ir pr'ó maneta (2007) refere essencialmente o ano de 1808, descrevendo Louis Henri Loison, o general dos exércitos franceses que participou nas três invasões e que ficou na memória popular e na história, sobretudo, pela sua total falta de escrúpulos no que tocava à apropriação em proveito próprio dos saques e impostos cobrados em zonas ocupadas e, em Portugal, pela dureza e crueldade com que tratava as populações submetidas. Loison não tinha um braço, daí ser "maneta" na expressão popular. O facto de ser impiedoso com os que afrontavam a ordem napoleónica valeu-lhe o escárnio popular e a expressão "ir pró maneta", significando ir e não voltar ou tudo perder, até a vida. "Logo no início - escreve Pulido Valente - a perseguição aos franceses e 'afrancesados' forneceu o pretexto para o assalto, busca e saque de centenas de casas (...) pelo simples facto de pertencerem aos 'ricos' e «poderosos»". ${ }^{2}$

Graça Moura, em 2008, retoma a temática das Invasões, descrevendo a sua novela O Pequeno-almoço do sargento Beauchamp como uma "novela que se lê bem e depressa" e explicando que "se trata de uma novela pela sua extensão e técnica narrativa, mais sincopada e sintética, sem a preocupação de definir com profundidade a psicologia das personagens". Aqui é narrado o facto histórico que se deu com o avô de Dona Antónia Ferreira, a "Ferreirinha" que, numa visita às suas propriedades foi interpelado por tropas francesas, e por falar correctamente francês, foi tomado como desertor e fuzilado.

Conhecendo uma de muitas histórias das Invasões, Graça Moura engendrou uma outra com um desfecho idêntico mas que tem lugar em Lisboa durante a permanência do general Junot. Nota-se que foi feito um estudo da época pois "a topografia da cidade era outra e até a medida do tempo, caminhos que se faziam apenas a pé, outros a cavalo e outros ainda apenas de carruagem". Para construir a novela, Graça Moura consultou documentação daquele tempo, nomeadamente as Memórias da Duquesa de Abrantes ou Luz Soriano, além do livro de Pulido Valente.

\footnotetext{
${ }^{2}$ http://www.cienciahoje.pt/index.php?oid=24402\&op=all
} 


\section{Conclusão}

A Literatura Francesa (com os três grandes movimentos que atravessam o século XIX: romantismo, realismo e simbolismo) influência de maneira definitiva a literatura portuguesa. Contudo, também na literatura nacional ficaram registadas as marcas, as manchas deixadas pelas tropas de Napoleão.

Daquilo que pudemos analisar relativamente à vasta bibliografia, pudemos concluir que encontrámos informação útil para melhor entender o ambiente vivido e sentido durante esse período conturbado. Não é apenas o exército francês que penetra em Portugal. Temos que relembrar a presença inglesa e espanhola, também ela tão forte. Existem, de resto, vários relatos de visitas de estrangeiros a Portugal antes e depois das Invasões (Georges Borron, Carlos Israel Riders, Heinric Friedricht Link, Marianne Baillie) que transmitem uma visão do país bem particular.

Aos ingleses e espanhóis juntaram-se ainda as Milícias e as Ordenanças, os bandos mais ou menos organizados de voluntários que tomaram de assalto um país que já vinha apresentando sinais de pobreza e instabilidade política e social. Nos anos seguintes, apareceriam ainda os exércitos liberais e os miguelistas, deixando o país numa enorme perturbação sociopolítica.

Para terminar, diria que esta época da história tão interessante e fecunda sofreu, de facto, muitas invasões: invasões sociais, politicas, culturais que foram dolorosas e marcantes e que foram transmitidas enquanto memória oral e de família de pais para filhos. E, na recuperação dessa memória da invasão em que o "ouvi contar", "ouvi dizer" ainda corre pelas aldeias portuguesas, interessa resgatar o fundo da verdade através das literaturas, não só para tornar os factos verdadeiros mas também para restabelecer a ordem perdida. 


\section{Bibliografia}

AIRES, Cristovão (1924). Dicionário Bibliográfico da Guerra Peninsular. Coimbra: Imprensa da Universidade.

ARANHA, Brito de (1909). Nota acerca das Invasões Francesas em Portugal, principalmente respeitante à primeira invasão do comando de Junot de Brito. Lisboa: Academia Real das Ciências.

AssIS, José Luís (2008). "A entrada do Corps d'Observation de la Gironde em Portugal (1807): Análise e interpretação dos relatos do Barão Thiébault, Tenente-General Chefe do Estado-Maior". In: Maria Leonor Machado de Sousa, A Guerra Peninsular: Perspectivas Mutidisciplinares, Volume II. Lisboa: Caleidoscópio, pp.73-94.

BerthiER, Patrick et JARRETTY, Michel (2006). Histoire de la France Littéraire. Paris : PUF. Bethencourt, Cardoso de (1910). Catálogo das Obras referentes à Guerra da Península. Lisboa: Academia das Ciências de Lisboa.

GraçA-MourA, Vasco (2008). O pequeno-almoço do Sargento Beauchamp. Lisboa: Alêtheia Editores.

MARCELIN, Jean-Baptiste Antoine (2006). Memórias sobre a 3ª Invasão. Lisboa:

Caleidóscopio.

MONGLON, André (1976). La France Révolutionnaire et Impériale. Annales de bibliographie méthodique et description des livres illustrés. Genève: Slatkine.

RATON, Jacome (1813). Recordacoens de Jacome Ratton, fidalgo cavalleiro da Caza Real, cavalleiro da ordem de Christo, ex-negociante da praça de Lisboa, e deputado do tribunal supremo da Real Junta do Commercio, Agricultura, Fabricas e Navegação. Sobre occurrencias do seu tempo, em Portugal, durante o lapso de sessenta e tres annos e meio, aliás de maio de 1747 a setembro de 1810, que rezidio em Lisboa: acompanhadas de algumas subsequentes reflexoens suas, para informaçoens de seus proprios filhos. Com documentos no fim. Londres: Blackfriars.

SoRIANO, Simão José da Luz, (1870). História da Guerra Civil e do estabelecimento do Governo Parlamentar compreendendo a história diplomática, militar e política, deste reino desde 1777 até 183. Lisboa: Imprensa Nacional.

TULLARD, Jean (1991). Nouvelle Bibliographie Critique des Mémoires sur l'Époque Napoléonienne écrits ou traduits en français. Genève: Droz.

VentuRA, António (2008). "Memórias Francesas sobre a Guerra Peninsular". In: Maria Leonor Machado de SouSA, A Guerra Peninsular: Perspectivas Mutidisciplinares, Volume II. Lisboa: Caleidoscópio, pp.57-71. 